\title{
Evaluation of ; Vivir Mi Vida! to improve health and wellness of rural-dwelling, late middle- aged Latino adults: results of a feasibility and pilot study of a lifestyle intervention
}

\author{
Stacey L. Schepens Niemiec ${ }^{1}$, Jeanine Blanchard ${ }^{1}$, Cheryl L. P. Vigen ${ }^{1}$, Jenny Martínez ${ }^{1}$, Laura Guzmán ${ }^{1}$, \\ Alyssa Concha ${ }^{1}$, Michelle Fluke ${ }^{2}$ and Mike Carlson ${ }^{1}$ \\ ${ }^{1}$ Mrs. T.H. Chan Division of Occupational Science and Occupational Therapy, University of Southern California, \\ Los Angeles, CA, USA \\ ${ }^{2}$ Antelope Valley Partners for Health, Lancaster, CA, USA
}

\begin{abstract}
Aim: The aim of this study was to determine the feasibility and efficacy of a culturally tailored lifestyle intervention, ; Vivir Mi Vida! (Live My Life!). This intervention was designed to improve the health and well-being of high risk late middle-aged Latino adults and to be implemented in a rural primary care system. Background: Rural-dwelling Latino adults experience higher rates of chronic disease compared with their urban counterparts, a disparity exacerbated by limited access to healthcare services. Very few lifestyle interventions exist that are both culturally sensitive and compatible for delivery within a non-metropolitan primary care context. Methods: Participants were 37 Latino, Spanish-speaking adults aged 50-64-years-old, recruited from a rural health clinic in the Antelope Valley of California. ; Vivir Mi Vida! was delivered by a community health worker-occupational therapy team over a 16-week period. Subjective health, lifestyle factors, and cardiometabolic measures were collected pre- and post-intervention. Follow-up interviews and focus groups were held to collect information related to the subjective experiences of key stakeholders and participants. Findings: Participants demonstrated improvements in systolic blood pressure, sodium and saturated fat intake, and numerous patient-centered outcomes ranging from increased well-being to reduced stress. Although participants were extremely satisfied with the program, stakeholders identified a number of implementation challenges. The findings suggest that a tailored lifestyle intervention led by community health workers and occupational therapists is feasible to implement in a primary care setting and can improve health outcomes in rural-dwelling, late middle-aged Latinos.
\end{abstract}

Key words: community-based research; community health worker; Latino; lifestyle intervention; occupational therapy; rural

Received 6 June 2017; revised 11 October 2017; accepted 15 December 2017;

first published online 6 May 2018

The number of Latino older adults in the United States is expected to surpass 14 million by the year 2050 (Vincent and Velkoff, 2010), which

Correspondence to: Stacey L. Schepens Niemiec, Mrs. T.H. Chan Division of Occupational Science and Occupational Therapy, University of Southern California, 1540 Alcazar St., CHP-133, Los Angeles, CA 90089, USA. Email: schepens@usc. edu corresponds to a $550 \%$ increase from 2017 . This demographic trend forebodes significant healthcare challenges given the high prevalence of chronic conditions such as obesity and diabetes in this population (Daviglus et al., 2012). Despite the high rate of disease, Latino elders have lower mortality rates than other ethnic groups. Unfortunately, this extended longevity in combination with high prevalence of chronic conditions results

(C) Cambridge University Press 2018 
in more years per capita in which disease or disability is present (Hayward et al., 2014).

Compounded by the aforementioned healthcare challenge, Latinos in rural communities comprise 9.3\% of the total US population (Housing Assistance Council, 2012) and, relative to urban-dwelling Latinos, experience additional health inequities such as greater prevalence of hypertension and type 2 diabetes (Koopman et al., 2006; Bale, 2010). These disparities stem from risk factors found in rural communities such as decreased health service availability and accessibility (Lutfiyya et al., 2012; 2013), shortages of healthcare professionals (Weinhold and Gurtner, 2014), economic disadvantages (Lutfiyya et al., 2013; Weinhold and Gurtner, 2014), and environmental barriers that impede physical activity (Swenson et al., 2005).

Interventions that utilize specialized strategies and adaptations have been proposed to effectively reach rural-dwelling individuals and address their unique health-related barriers. Examples of these recommendations include building local partnerships to support implementation, offering telemedicine, accommodating long-distance travel, integrating services into primary care, seeking aid from 'natural helpers' in the community, and broadening providers' skillsets to make up for service shortages (Chipp et al., 2008; Lutfiyya et al., 2012; Calancie et al., 2015). Community-based lifestyle interventions that are both designed for delivery in a rural setting and sensitive to Latino culture, though not great in number, have successfully achieved such outcomes as enhanced glycemic control and engagement in health behaviors (Goldhaber-Fiebert et al., 2003; Sanchez et al., 2014).

Despite promising results for culturally sensitive, rural community-targeted interventions, efficacy has not been studied through the lens of patient-centered outcomes. Such outcomes were recognized as a priority in the Patient Protection and Affordable Care Act of 2010 and commonly incorporate psychosocial concerns that reflect individuals' preferences, feelings, needs, and functional status (Rubenfeld, 2003). Examples of patient-centered outcomes include activity participation, sleep quality, stress, and symptom management. Use of such outcomes complements conventional physiological measures (Verhoef et al., 2005). Patient-centered outcomes not only correlate with traditional, objective outcomes such as cardiovascular risk profile (De Smedt et al., 2013) and cognitive functioning (Scullin and Bliwise, 2015), but also provide a more complete picture of health and well-being.

In this study, the feasibility and efficacy of a culturally tailored lifestyle intervention, $;$ Vivir $M i$ Vida! (;VMV!; Live My Life!), intended to improve the health and well-being of high risk 50-64-year-old Latino adults, was pilot tested. This activity-centered intervention was delivered by partnered community health workers (CHWs) and occupational therapists (OTs) within the context of a primary care system. A preliminary qualitative needs assessment resulted in identification of a set of patient-valued health domains and health promotion strategies that informed ; $V M V$ ! module construction (Schepens Niemiec et al., 2015). iVMV! was then adapted by incorporating strategies for rural healthcare delivery such as a strong reliance on home-based sessions, use of telemedicine, and a focus on local resources and supports. It was hypothesized that the adapted intervention would be feasible to administer and improve both physiologic and patientcentered health-related outcomes in the target population. In addition, it was hypothesized that key stakeholders - including intervention supervisors, CHWs, assessors, and the partnering community wellness organization administrator would be satisfied with the program and view it as practical to implement in their community.

\section{Method}

\section{Design}

Study procedures were approved by the University of Southern California (USC) Institutional Review Board. The design entailed a one-arm, feasibility and pre-post pilot efficacy study of the rural-adapted program in the Antelope Valley of California during 2016. Antelope Valley is located in northern Los Angeles County and comprises the western tip of the Mojave Desert.

\section{Participants \& setting}

A total of 40 eligible participants were recruited between February and March 2016 through randomized selection of referred patients listed as potentially eligible by the partnering health clinic (Antelope Valley Community Clinic [AVCC]), as 
well as through community information booths, word-of-mouth, and flyers. Inclusion criteria limited enrollment to individuals who were 50-64-years-old, Latino, fluent in Spanish (to facilitate group session interactions), available by phone, and oriented to person, place, and time. In addition, participants were required to have visited AVCC during the past year, with self-reported capacity to complete a 16-week intervention and no plans to move outside of Antelope Valley within six months. The decision to target late middle-aged adults was based on: (a) recent theory, which emphasizes healthy aging as a continuous process throughout the lifespan (Hansen-Kyle, 2005); (b) the desirability of instilling sound health habits during a temporal window that precedes major health declines experienced in older age (Sudano and Baker, 2006); and (c) indications that Latino adults in this age group are willing to undertake health-promoting lifestyle changes (Osuna et al., 2011; Schepens Niemiec et al., 2015).

\section{Procedure}

Greater detail of all study procedures can be found in (Schepens Niemiec et al., In Press). With support from AVCC, this community-based participatory research was conducted in partnership with Antelope Valley Partners for Health (AVPH), a community wellness organization located in Antelope Valley. AVPH supplied two CHW interveners who were Spanish-English bilingual. The USC research team provided two bilingual intervener supervisors: a treating OT and senior promotor (ie, a CHW who has deep ties to the Latino community, specialized cultural knowledge, and shared lived experiences; Latino Health Access et al., 2011). The USC team led 12- and 40-h training workshops for the assessors and intervening CHWs, respectively.

Participants were screened for eligibility primarily by telephone and subsequently consented and enrolled in person. Using schedule availability, individuals were allocated to one of four intervention groups $(n=10$ per group; two groups per $\mathrm{CHW})$. Assessments took place at baseline (pretest) and post-intervention (posttest).

\section{Data collection \& instruments}

Table 1 summarizes the tools/indices and study variables used to evaluate intervention efficacy. Assessors collected data at each time point (unless otherwise noted) typically at participants' homes.
All pre-existing assessments had been validated for Latino populations and were available in Spanish. The primary patient-centered outcomes consisted of sub-scores on the Measure Yourself Medical Outcome Profile 2 (MYMOP2; Paterson, 1996). MYMOP2 is a patient-centric questionnaire that requires respondents to identify one or two current and personally bothersome symptoms. Participants rate symptom severity, as well as how much each symptom interferes with daily activities and well-being. The MYMOP2 produces an overall profile score as well as sub-scores of symptom severity, general well-being, and impact of symptoms on daily activity. Secondary outcomes ranged from lifestyle factors (eg, physical activity engagement) to cardiometabolic measures (eg, cholesterol level). Comorbidity information was collected via self-report and from AVCC electronic medical records. Assessors entered selfreported data obtained orally and cardiometabolic measurements into Research Electronic Data Capture (REDCap) - a web-based application to support data collection (Harris et al., 2009).

\section{Intervention}

As described in Schepens Niemiec et al. (In Press), ;VMV! integrated theoretical constructs from (a) OT Lifestyle Redesign ${ }^{\circledR}$ - holistic wellness, habits and routines, and participation in culturally defined activities (Carlson et al., 1998; Clark et al., 2015); and (b) social cognitive theory self-efficacy, self-regulation, social support, and outcome expectations (Bandura, 1986; 2004). Intervention delivery was also underpinned by behavior change techniques such as goal-setting, building social support, acknowledging past successes, and educating individuals about the consequences of behavior (Michie et al., 2011).

¡ $V M V$ ! utilized $\mathrm{CHWs}$ as frontline interveners who were supervised by a senior promotor-OT team. The supervising promotor educated the CHWs about community health outreach, provided community resources and supports for participants, and assisted the CHWs in delivering content in a culturally sensitive and understandable manner. The OT held a dual role as a supervisor and clinical interventionist. As a supervisor, the OT facilitated the CHWs' use of health behavior change techniques and guided the CHWs in grading and adapting participants' activities to support long-term goal 
Table 1 Overview of study variables and data collection tools/procedures used to evaluate intervention efficacy

\begin{tabular}{|c|c|c|c|c|}
\hline Category & Variable(s) & Method of measurement & Description & References \\
\hline $\begin{array}{l}\text { Background and } \\
\text { demographics }^{a}\end{array}$ & $\begin{array}{l}\text { Age, country of birth, employment } \\
\text { status, ethnicity, household income, } \\
\text { living arrangement, marital status, } \\
\text { race, sex, smoking status and } \\
\text { behavior, years living in United } \\
\text { States, years of schooling }\end{array}$ & $\begin{array}{l}\text { Study-specific demographic/ } \\
\text { background questionnaire }\end{array}$ & $-{ }^{a}$ & - \\
\hline \multirow[t]{3}{*}{ Anthropometrics } & Weight & Standard weight scale & - & - \\
\hline & Height $^{\mathrm{b}}$ & Stadiometer & - & - \\
\hline & Waist and hip circumference & Measuring tape & - & \\
\hline \multirow[t]{5}{*}{$\begin{array}{l}\text { Patient-centered } \\
\text { measures }\end{array}$} & $\begin{array}{l}\text { Patient-centered outcomes } \\
\text { (primary outcome) }\end{array}$ & $\begin{array}{l}\text { Measure yourself medical } \\
\text { outcome profile (MYMOP2) }\end{array}$ & $\begin{array}{l}\text { Symptom severity, symptom } \\
\text { interference with daily activities, } \\
\text { and well-being }\end{array}$ & $\begin{array}{l}\text { Paterson, (1996), Paterson } \\
\text { et al. (2000), Polus et al. } \\
\text { (2011) }\end{array}$ \\
\hline & Social health satisfaction & $\begin{array}{l}\text { Satisfaction with participation in } \\
\text { social roles - short form } 7 a \text { and } \\
\text { Satisfaction with participation in } \\
\text { discretionary social activities - } \\
\text { short form 7a }\end{array}$ & $\begin{array}{l}\text { Satisfaction with performing usual } \\
\text { social roles and activities }\end{array}$ & Cella et al. (2010) \\
\hline & Sleep disturbance & $\begin{array}{l}\text { Pittsburgh sleep quality index } \\
\text { (PSOI) }\end{array}$ & $\begin{array}{l}\text { Global sleep quality, sleep quality, } \\
\text { sleep latency, sleep duration, } \\
\text { habitual sleep efficiency, sleep } \\
\text { disturbance, use of sleeping } \\
\text { medications, and daytime } \\
\text { dysfunction }\end{array}$ & $\begin{array}{l}\text { Backhaus et al. (2002), } \\
\text { Cole et al. (2006) }\end{array}$ \\
\hline & Stress & Elo et al.'s single item stress index & General level of stress 'these days' & Elo et al. (2003) \\
\hline & Patient activation ${ }^{\mathrm{C}}$ & $\begin{array}{l}\text { Patient activation measure } \\
\text { 13-item short form (PAM-13) }\end{array}$ & $\begin{array}{l}\text { One's knowledge of, skills in, and } \\
\text { confidence in health self- } \\
\text { management }\end{array}$ & Hibbard et al. (2005) \\
\hline \multirow[t]{2}{*}{ Lifestyle } & Dietary intake & $\begin{array}{l}\text { Block } 2005 \text { food frequency } \\
\text { questionnaire Spanish version }\end{array}$ & $\begin{array}{l}\text { Usual and customary intake of a wide } \\
\text { array of nutrients and food groups }\end{array}$ & $\begin{array}{l}\text { Centers for Disease Control } \\
\text { and Prevention (2015) }\end{array}$ \\
\hline & Physical activity engagement & $\begin{array}{l}\text { International physical activity } \\
\text { questionnaires (IPAQ) }\end{array}$ & $\begin{array}{l}\text { Vigorous activity, moderate activity, } \\
\text { walking, and time spent sitting }\end{array}$ & Craig et al. (2003) \\
\hline \multirow[t]{3}{*}{ Clinical health } & Comorbidity ${ }^{c},{ }^{d}$ & $\begin{array}{l}\text { Charlson comorbidity index } \\
\text { calculated from electronic } \\
\text { medical record diagnoses }\end{array}$ & Comorbidity status & Charlson et al. (1987) \\
\hline & Hemoglobin A1c & $\begin{array}{l}\text { Afinion meter (Alere, Inc., } \\
\text { Waltham, MA, USA) }\end{array}$ & Non-fasting & - \\
\hline & $\begin{array}{l}\text { Lipid profile } \\
\text { Blood pressure }\end{array}$ & $\begin{array}{l}\text { Cholestech meter (Alere, Inc.) } \\
\text { Digital blood pressure monitor }\end{array}$ & $\begin{array}{l}\text { Non-fasting } \\
\text { Seated and resting }\end{array}$ & - \\
\hline \multirow[t]{2}{*}{ Disease risk } & Coronary heart disease risk ${ }^{d}$ & $\begin{array}{l}\text { Framingham risk score LDL points } \\
\text { total }\end{array}$ & - & Wilson et al. (1998) \\
\hline & Diabetes risk $^{\mathrm{c}}$ & $\begin{array}{l}\text { European prospective } \\
\text { investigation into cancer and } \\
\text { nutrition diabetes risk score } \\
\text { (EPIC) }\end{array}$ & - & Schulze et al. (2007) \\
\hline
\end{tabular}


attainment. As part of the OT's clinical role, she reviewed health information from the electronic medical record, concatenating it with treatment; monitored participants' activity participation, and discussed with individuals integration of healthful routines. Digital communication was established between the CHW-OT team and participants' primary care physicians to report health-related updates. The senior promotor and OT held weekly supervisory sessions with the CHWs to discuss participant cases, implementation challenges, and forthcoming sessions.

The first intervention session included a home visit with a $\mathrm{CHW}$, combined with a telemedicine OT consultation. During this session, the participant created a personalized health action plan (HAP), which was revisited at subsequent sessions. CHWs led weekly visits (including seven one-onone home sessions, two group sessions held at local community facilities, and two telephone check-ins) over 16 weeks. In addition, the OT provided two 20-min telephone consultations to discuss individually experienced wellness facilitators, as well as troubleshoot barriers to health-related goals.

CHWs were provided with a structured manual, supplemented with a picture-based flip-over booklet and demonstration tools. Participants were given health-related materials and tools throughout the program such as a Garmin Vivofit activity monitor and a measuring cup. Overarching modular topics included healthy eating and physical activity, healthcare navigation, chronic disease management, and mental well-being.

\section{Data analysis}

All analyses were organized using a rubric that addresses pilot interventions' feasibility based on scientific merit (efficacy results) and study processes, resources, and management (Thabane et al., 2010). Given $10 \%$ attrition, use of a twotailed test with $\alpha=0.05$, and an effect size of 0.454 , a sample size of 40 was required to achieve $80 \%$ power for detecting change on a continuous outcome variable. Similar interventions (Parikh et al., 2010; Koniak-Griffin et al., 2015) suggested an effect size of 0.454 would be appropriate for examining efficacy. Wilcoxon signed rank tests were used to compare pre- and post-intervention scores on primary and secondary outcomes. Statistical analyses were performed using SAS 9.4 for windows (SAS, Cary, NC, USA).

\section{Feasibility evaluation $\&$ analysis}

Feasibility was assessed using a mixed-methods process evaluation that considered viewpoints of participants, stakeholders, and the study team. Immediately after the posttest, assessors queried each participant about program feasibility and acceptability using a semi-structured interview guide and Likert-style survey. In addition, all participants were invited to attend one of two focus groups - led by experienced qualitative researchers who were unrelated to the study - to further discuss their intervention experiences. A research assistant took detailed field notes during these groups. Slightly less than one-half of the participants attended the groups $(n=7$ and $n=8)$, which resulted in sizes optimal for group interaction (Patton, 2001). In addition, stakeholders (ie, intervention supervisors, CHWs, assessors, and AVPH administrator) were queried using semi-structured interviews. All interviews and focus groups were audio-recorded.

Fidelity of intervention delivery by the CHWs was assessed by the supervising OT using a study-specific index that listed theoretically postulated core content and processes comprising iVMV! (Schepens Niemiec et al., In Press for details). Intervention elements such as culturally sensitive delivery of materials or attention to a participant's personal support system were rated as 'completed,' 'not completed,' 'unsure,' or 'not applicable.' The OT applied the fidelity index during two individual and two group sessions per CHW, as well as during two audio-recorded individual sessions (randomly selected, but contingent upon participant permission). Finally, feasibility was assessed through recruitment logs, daily correspondences, attendance reports, and adverse event logs.

Focus group and interview audio recordings were transcribed, and translated to English as necessary. Using Dedoose (Version 7.5.9) web application for qualitative data (SocioCultural Research Consultants, 2017), a surface-level content analysis (Berg, 2001) was conducted to identify themes specific to feasibility. This type of analysis permits classification of qualitative information using a predetermined coding scheme. Two research team members generated codes independently, which were later checked by a third member and stored in a master codebook. Analysts documented decision pathways for purposes of maintaining an audit trail of analytic memos. 
Quantitative data resulting from participant interviews and supplemental sources (eg, attendance logs) were summarized via descriptive statistics. Because the present study did not involve comprehensive qualitative procedures, alternative in-depth analyses methods were not warranted. Thabane and colleagues' (2010) recommended organizational structure and rubric for evaluating pilot studies served as overarching themes under which both quantitative and qualitative information was filed. Doing so enabled efficient integration of mixed-methods data that are easily compared across studies that have used a similar thematic scaffold.

\section{Results}

\section{Study sample}

Table 2 describes characteristics of participants who completed post-testing $(n=37)$. Age ranged from 50.7 to 64.9 years. Most participants were female $(n=34,91 \%)$, born outside of the United States $(n=36,97 \%)$, non-smoking $(n=28,76 \%)$, and/or unemployed $(n=28,76 \%)$. The mean body mass index $(32.1 \pm 6.5)$ fell within the range of Class I obesity (Nuttall, 2015). All participants reported an income of less than US\$24 000/year. Information on comorbidities was collected from complete electronic medical record data $(n=27)$ and selfreport questionnaires $(n=33)$. Of participants with electronic medical record data, more than half were diagnosed with pain $(n=21,78 \%)$, dyslipidemia $(n=18,67 \%)$, diabetes $(n=15,56 \%)$, and gastrointestinal/liver disease $(n=14,52 \%)$. Charlson comorbidity indices for those with electronic medical record data ranged from $0(44 \%)$ to $4(4 \%)$, with a mean score of $1.1 \pm 1.2$. Common self-reported conditions included dyslipidemia $(n=18,55 \%)$, arthritis $(n=14,42 \%$ versus $11 \%$ in electronic medical records), diabetes $(n=13,39 \%)$, depression $(n=12,36 \%$ versus $19 \%$ in electronic medical records), and hypertension $(n=12,36 \%$ versus $18 \%$ in electronic medical records).

\section{Scientific feasibility}

No intervention-related adverse events occurred. Patient-centered outcomes improved significantly $(P \leqslant 0.01)$ from pretest to posttest (Table 3) for the overall MYMOP2 profile score and subscales (ie, symptom severity, symptom impact on activity,
Table 2 Characteristics of pilot study participants at pretest $(n=37)$ who completed post-testing

\begin{tabular}{|c|c|}
\hline Characteristic & $M \pm \mathrm{SD}$ or $n(\%)$ \\
\hline Age (years) & $58.2 \pm 4.8$ \\
\hline Sex: female & $34(91.1 \%)$ \\
\hline \multicolumn{2}{|l|}{ Birthplace } \\
\hline United States & $1(2.7 \%)$ \\
\hline Mexico & $24(64.9 \%)$ \\
\hline Other & $12(32.4 \%)$ \\
\hline \multicolumn{2}{|l|}{ Education level } \\
\hline$<$ High school & $20(54.1 \%)$ \\
\hline High school degree & $13(35.1 \%)$ \\
\hline Some college, business, or trade & $4(10.8 \%)$ \\
\hline College graduate + & 0 \\
\hline \multicolumn{2}{|l|}{ Household income } \\
\hline$\leqslant$ US\$999/month & $22(62.9 \%)$ \\
\hline US\$1000-1999/month & $13(37.1 \%)$ \\
\hline \multicolumn{2}{|l|}{ Years in United States } \\
\hline$\leqslant 20$ years & $8(22.2 \%)$ \\
\hline$>20$ years & $28(77.8 \%)$ \\
\hline \multicolumn{2}{|l|}{ Relationship status } \\
\hline Married/committed & $23(62.2 \%)$ \\
\hline Single/widowed/divorced & $14(37.8 \%)$ \\
\hline \multicolumn{2}{|l|}{ Living status } \\
\hline Alone & $4(10.8 \%)$ \\
\hline With others & $33(89.2 \%)$ \\
\hline \multicolumn{2}{|l|}{ Employed } \\
\hline No & $28(75.7 \%)$ \\
\hline Yes ( $M$ hours/week) & $9(24.3 \%)[23.2]$ \\
\hline \multicolumn{2}{|l|}{ Smoking status } \\
\hline Current & $0(0 \%)$ \\
\hline Former & $9(24.3 \%)$ \\
\hline Never & $28(75.7 \%)$ \\
\hline \multicolumn{2}{|l|}{ Insurance } \\
\hline Medi-Cal & $33(89.2 \%)$ \\
\hline Private or other & $4(10.8 \%)$ \\
\hline \multicolumn{2}{|l|}{ Emergency room visit past 12 months } \\
\hline No & $20(55.6 \%)$ \\
\hline Yes & $16(44.4 \%)$ \\
\hline \multicolumn{2}{|l|}{ Hospitalized past 12 months } \\
\hline No & $27(75.0 \%)$ \\
\hline Yes & $9(25.0 \%)$ \\
\hline Body mass index $\left(\mathrm{kg} / \mathrm{m}^{2}\right)$ & $32.1 \pm 6.5$ \\
\hline
\end{tabular}

and well-being), with all effect sizes mediumto-large (0.50-1.06). Results for secondary outcomes are presented in Table 4. Participants improved significantly for the patient-centered outcomes of stress, satisfaction with social roles, and satisfaction with social activity (effect sizes = 0.39-0.45). Relative to clinical health, participants' systolic blood pressure improved $(P=0.006)$. Other outcomes such as weight, HbA1c, cholesterol level, and diabetes and cardiovascular disease risk did not change. Regarding lifestyle behaviors, intake of sodium and saturated fat decreased significantly 
Table 3 Measure yourself medical outcome profile (MYMOP2) scores from pretest to posttest

\begin{tabular}{|c|c|c|c|c|c|c|c|c|}
\hline \multirow[b]{2}{*}{ Outcome } & \multicolumn{3}{|c|}{ Pretest } & \multicolumn{3}{|c|}{ Posttest } & \multirow[b]{2}{*}{$P^{\mathrm{a}}$} & \multirow[b]{2}{*}{ Effect size $(d)^{\mathrm{b}}$} \\
\hline & $n$ & $M$ & SD & $n$ & $M$ & SD & & \\
\hline MYMOP2 profile & 36 & 4.7 & 1.2 & 37 & 3.5 & 1.4 & $<0.0001$ & -0.95 \\
\hline Symptom 1 severity & 36 & 5.1 & 1.3 & 37 & 3.7 & 1.9 & $<0.0001$ & -1.04 \\
\hline Symptom 2 severity & 25 & 5.2 & 1.5 & 26 & 3.7 & 2.0 & 0.005 & -0.92 \\
\hline Activity impact & 29 & 4.8 & 1.9 & 30 & 3.7 & 1.7 & 0.008 & -0.74 \\
\hline Well-being & 31 & 4.2 & 1.7 & 34 & 3.3 & 1.6 & 0.01 & -0.49 \\
\hline
\end{tabular}

A decrease in scores is considered improvement.

${ }^{a}$ Wilcoxon signed rank test.

Table 4 Changes in secondary outcomes from pretest to posttest

\begin{tabular}{|c|c|c|c|c|}
\hline Outcome & Pretest $[M(S D)]$ & Posttest [M(SD)] & $P^{a}$ & Effect size $(d)$ \\
\hline Weight (kg) & 79.5 (17.9) & $78.8(16.6)$ & 0.25 & -0.04 \\
\hline Waist (cm) & $105.5(12.1)$ & $104.4(12.1)$ & 0.12 & -0.09 \\
\hline Hips (cm) & $116.8(13.2)$ & $115.6(13.1)$ & 0.41 & -0.09 \\
\hline \multicolumn{5}{|l|}{ Blood pressure } \\
\hline Systolic & $130.5(16.7)$ & $122.6(16.4)$ & 0.006 & -0.47 \\
\hline Diastolic & $76.3(10.7)$ & $74.6(8.8)$ & 0.31 & -0.16 \\
\hline HbA1c among diabetics ${ }^{b}$ & $7.8(1.7)$ & $8.4(2.5)$ & 0.25 & 0.30 \\
\hline \multicolumn{5}{|l|}{ Cholesterol $^{\mathrm{c}}$} \\
\hline Triglycerides & $207.9(103.1)$ & $198.9(71.9)$ & 0.47 & -0.15 \\
\hline $\mathrm{HDL}$ & $47.0(10.1)$ & $42.1(10.1)$ & 0.07 & -0.42 \\
\hline LDL & $98.9(27.7)$ & $99.0(35.6)$ & 0.66 & -0.03 \\
\hline Total & $184.8(30.7)$ & $180.4(40.5)$ & 0.61 & -0.20 \\
\hline Coronary heart disease risk $^{d}$ & $0.09(0.06)$ & $0.10(0.07)$ & 0.63 & 0.07 \\
\hline Diabetes risk ${ }^{\mathrm{e}}$ & $560.2(117.2)$ & $586.3(71.4)$ & 0.21 & 0.20 \\
\hline Stress & $3.2(1.5)$ & $2.6(1.4)$ & 0.02 & -0.39 \\
\hline Sleep disturbance & $8.9(4.9)$ & $7.4(4.5)$ & 0.07 & -0.30 \\
\hline \multicolumn{5}{|l|}{ Physical activity engagement } \\
\hline MET (minutes/week) & $2801.2(3677.5)$ & $2013.4(3235.0)$ & 0.25 & -0.21 \\
\hline Health enhancing activity & $1.9(0.9)$ & $1.8(0.8)$ & 0.90 & -0.03 \\
\hline Social roles satisfaction & $21.8(7.6)$ & $25.1(7.6)$ & 0.001 & 0.43 \\
\hline Social activity satisfaction & $19.6(6.0)$ & $22.2(7.2)$ & 0.002 & 0.43 \\
\hline \multicolumn{5}{|l|}{ Daily dietary intake } \\
\hline Sugar $(g)$ & $78.8(44.9)$ & $63.7(35.3)$ & 0.07 & -0.31 \\
\hline Sodium (mg) & $3120(1741)$ & $2168(925)$ & 0.0001 & -0.51 \\
\hline Saturated fat $(\mathrm{g})$ & $22.3(11.6)$ & $14.8(6.1)$ & $<0.0001$ & -0.59 \\
\hline Vegetables (servings) & $2.3(1.7)$ & $2.1(1.3)$ & 0.50 & -0.13 \\
\hline Fruit (servings) & $1.1(0.8)$ & $1.4(1.0)$ & 0.24 & 0.30 \\
\hline Patient activation & - & $73.4(19.0)$ & - & - \\
\hline
\end{tabular}

$\mathrm{HDL}=$ high density lipoprotein; MET = metabolic equivalent; $n=36-37$, unless otherwise indicated.

a Wilcoxon signed rank test with significant values bolded.

${ }^{\mathrm{b}}$ Of participants diagnosed as diabetic $(n=18), \mathrm{HbA} 1 \mathrm{c}$ was available for 11 participants at pretest, 18 at posttest and 11 for both time-points.

${ }^{\mathrm{c}}$ Cholesterol values were available for 15 participants at pretest, 28 at posttest, and 14 for both time-points.

${ }^{\mathrm{d}}$ Coronary heart disease risk scores are the 10-year congenital heart disease risk; values were available for 15 participants at pretest, 28 at posttest, and 14 for both time-points.

e Diabetes risk scores of 534-585 and 586-657 are associated with 3.0-4.9\% and 5.0-9.9\% incidence of diabetes within five years, respectively; values are calculated only for non-diabetics and were available for 16 participants at pretest, 17 at posttest, and 16 for both time-points. 
$(P \leqslant 0.0001)$ and sugar consumption showed a marginally significant reduction $(P=0.07)$, but no significant changes were noted for physical activity engagement. Reductions in systolic blood pressure were associated with reduced intake of sodium $(r=0.43, \quad P=0.01)$ and saturated fat $(r=0.43$, $P=0.01)$; data not shown.

\section{Process feasibility}

\section{Recruitment, retention, \& adherence}

Recruitment and retention data are presented in Figure 1. A total of 74 potentially eligible individuals were screened: 14 failed to meet inclusion criteria, eight declined participation, and 12 were excluded for other reasons such as unresponsiveness to repeated telephone messages. In all, 37 participants $(93 \%)$ completed post-testing.
Participant adherence was defined as percent completion of all possible intervener contacts $(n=15)-$ including individual, group, telephone, and OT sessions - within the 16-week program. We operationalized 'successful' adherence as $\geqslant 75 \%$ completion of all contact opportunities based on a similar study (de Heer et al., 2015). Adherence averaged $77 \%$ for all session types, $88 \%$ for individual sessions, $61 \%$ for group sessions, and $76 \%$ for telephone check-ins. Participants received an average of two of the three intended OT consultations.

\section{Fidelity}

With $\geqslant 80 \%$ integrity constituting 'high' and $\leqslant 50 \%$ representing 'low,' session fidelity (Perepletchikova and Kazdin, 2005) the CHWs delivered the majority of ; $V M V$ ! with high fidelity (when items were applicable). Nine of the 12 fidelity

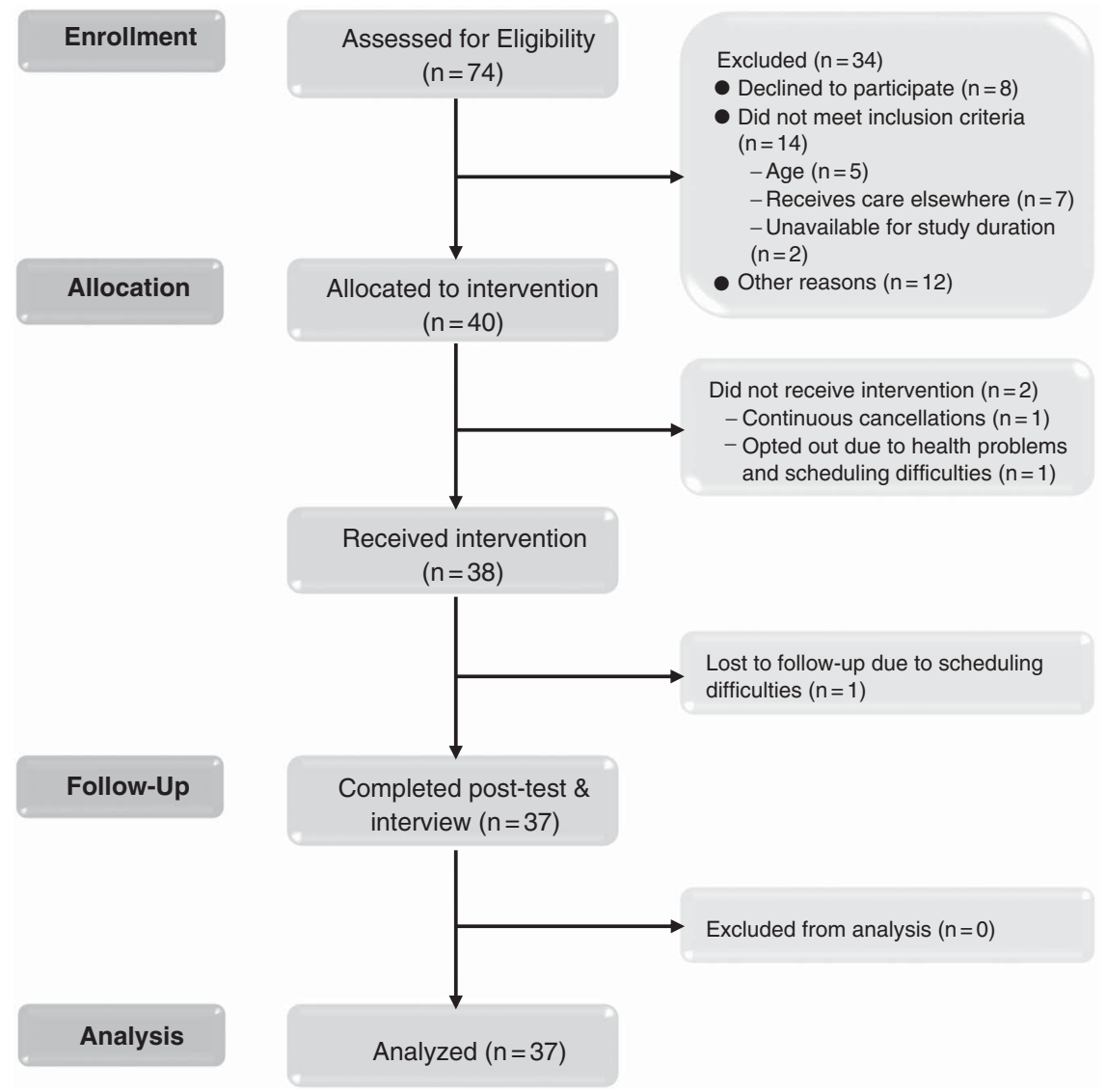

Figure 1 Recruitment and retention of participants 
items the OT reviewed were rated as performed properly $\geqslant 85 \%$ of the time. The OT noted that the CHWs engaged in participant-skill building only $71 \%$ of the time. One area in need of improvement was the CHWs' confidence and ability to deliver the intervention fluently in Spanish (Spanish was their second language); the OT rated this as occurring only $20 \%$ of the time. In addition, the CHWs did not utilize motivational interviewing techniques in any of the reviewed sessions.

\section{Implementation alterations}

Over the course of the study, the team made three major alterations to ; $V M V$ !. First, although the intervention was originally designed to be delivered by promotores, the limited supply of qualified personnel in the targeted rural area made it necessary to broaden intervener eligibility more generally to Spanish-speaking CHWs. To prevent this change from compromising the program's cultural sensitivity, our promotor devoted more attention during supervisory sessions to guiding the CHWs in delivering ; $V M V$ ! in a culturally competent manner. The second alteration occurred shortly after the onset of implementation and consisted of allowing participants to schedule make-up sessions outside of the intended sequence of intervention modules or to attend alternate group sessions when experiencing scheduling conflicts. Finally, the intervention manual was originally in English. Based on feedback from the CHWs during their training, we generated a certified translation of the manual so that the CHWs could more easily conduct sessions in Spanish. Other, more minor modifications are noted below in the discussions of implementation barriers and resource and management feasibility.

\section{Implementation facilitators \& barriers}

The following implementation facilitators were noted by CHWs: (a) adjusting supervisory meetings to provide more review of content for upcoming sessions; (b) having the supervising OT available to discuss health-related issues that fell outside of the CHWs' scope of practice; and (c) conducting individual sessions in participants' homes. Participants strongly endorsed the last item, stating that in-home sessions reduced the need to travel, making it easier for them to engage in program activities. Though some participants viewed inhome sessions as affording privacy that fostered trust, confidence, and more intimate interactions, others equally valued group sessions as an opportunity to receive peer support. Participants also shared that simply knowing that someone cared about them provided them with needed encouragement to carry out health behaviors. Finally, participants described that CHWs' demonstrations and activities (eg, measuring food portions, reading nutritional labels) were very helpful.

Implementation barriers largely revolved around resource limitations (see Resource Feasibility); however, process-related issues were also noted. The CHWs felt that the required computerized session documentation was too challenging, including the volume of data they were obligated to record and the process of uploading image captures of handwritten forms. To lessen this burden, the documentation process was streamlined midintervention. The CHWs also expressed feelings of being overloaded due to issues such as scheduling difficulties, partly stemming from packed caseloads, and having to spend time on evenings and weekends to offset laggard notes. In addition, they articulated uneasiness in covering topics outside of their comfort zones such as money management or grief; topics that are commonly addressed by OTs but not by CHWs. Finally, participants reported some process-related implementation barriers: (a) difficulty attending groups due to transportation challenges; (b) limited time to delve into intervention topics because the program was short; and (c) trouble activating and using the Garmin Vivofit activity monitors given to them in week 4, due to not having a computer or smartphone.

\section{Satisfaction, acceptability, \& adoption}

On a $0-10$ scale, participant satisfaction with the overall ; $V M V$ ! experience was high $(M=9.4 \pm 1.8)$; $81 \%$ of respondents rated the program as 10 . When asked about the acceptability of different intervention components, participants responded almost exclusively with highly positive feedback (Table 5). One participant stated, 'They explain everything very meticulously and you learn, like the program is named, how to live your life individually and how to start trusting in yourself, in people, and [...] live day by day.' They expressed 
Table 5 Descriptive statistics for participant satisfaction survey post-intervention $(n=37)$

\begin{tabular}{lll}
\hline Survey item (0-10 scale) & $\begin{array}{l}\text { Mean } \\
\text { rating }\end{array}$ & SD \\
\hline Handouts were helpful & 9.4 & 1.2 \\
Picture cards were helpful & 9.7 & 0.9 \\
Health action plan was helpful & 9.5 & 1.3 \\
Demonstration tools were helpful & 9.7 & 0.7 \\
Community health worker's ability to instill & 9.9 & 0.5 \\
$\quad$ understanding & 9.8 & 0.5 \\
iVivir Mi Vida! met your health needs & 9.8 & 0.6 \\
iVivir Mi Vida! met health needs of the & & \\
Hispanic community & 9.4 & 1.8 \\
Overall experience in ; VMV! & & \\
\hline
\end{tabular}

intense appreciation for ; $V M V$ !, with many describing the provision of the program as a 'gift from God' to the community. One individual suggested making i $V M V$ ! the focal point of a community health program: 'I would like for there to be an institution that has programs like this, but in the center it would be ;Vivir Mi Vida!'. Participants' willingness to adopt healthier lifestyles on a more long-term basis was also promising. One participant noted, 'I can utilize what I learned here for the rest of my life, because you stay with it for the rest of your life.'

Though not to the same degree as participants, the stakeholders also disclosed high satisfaction with iVMV!. For example, the CHWs felt that iVMV! offered social and emotional support that was much needed in the rural population. The AVPH administrator said that her organization was eager to adopt health programs for older people, including $; V M V !$, because seniors in Antelope Valley are in dire need of support for their well-being.

\section{Resource feasibility}

The feasibility of ; $V M V$ ! was chiefly dictated by the level of available resources (ie, time, space, equipment/materials, budget, and personnel). Accordingly, stakeholders' and participants' views about implementation barriers often focused on resource limitations. The $\mathrm{CHWs}$ expressed that the time needed to travel between participants' homes was burdensome due to Antelope Valley's vastness. Stakeholders all stated a desire for more time - for session and program length - to cover a greater range and depth of content; participants echoed this request. The promotor and OT supervisors pointed out that supervisory meetings, designed to assist CHWs in intervention delivery, were oftentimes cut short or canceled due to priority being placed on the CHWs' completion of participant sessions and documentation. The OT noted that this lack of time to communicate with the CHWs hindered her ability to provide an adequate level of informed support and intervention individualization.

With regard to space, the CHWs raised no concerns about securing a central location for group sessions. However, some participants indicated that having closer venues for group meetings would have been preferable due to the lengthy travel requirements for those living in outlying communities and/or relying on public transportation. The stakeholders and project management team alike expressed frustrations with equipment, including technological complexity of the physical activity monitors that were given to participants; videoconferencing using study laptops, which was often impeded by unreliable Wi-Fi signals, thus requiring communication via phone; and necessity to share certain equipment and materials among multiple personnel.

Budgetary and personnel resources were closely linked. Limited funding hampered implementation feasibility by posing personnel challenges in meeting the deadline for intervention completion, which resulted in the CHWs having heavy caseloads. Accordingly, during implementation, we discovered the need for a third CHW intervener to ensure the full dosage of intervention delivery. Having a third intervener proved necessary after one of the CHWs required a short leave of absence, and when participant schedules did not align with the availability of the two primary interveners. Given budgetary constraints and shortages of Spanish-speaking personnel at AVPH, we allowed the supervising promotor to serve as a back-up intervener. Nevertheless, the AVPH administrator discussed difficulties with not having additional AVPH staff cross-trained as a back-up for the CHWs, which limited program flexibility.

\section{Management feasibility}

Managing the overall project and intervention from a distance without an onsite project coordinator was particularly challenging. For example, communication with community partners occurred 
primarily through long email chains and phone texts, sent from multiple study team members. AVPH stakeholders voiced frustration with this system, stating that the messages they received were overwhelming in number and were occasionally overlapping or contradictory. In response, communication was streamlined by splitting up responsibilities among our study team and limiting the number of sent messages. Bi-weekly phone check-ins with the AVPH administrator were also arranged to ensure the project was running smoothly for both AVPH and USC personnel. Importantly, the AVPH administrator brokered contact between the study team and administration at AVCC. The pre-established relationships with community partners greatly enhanced the ease of completing mandatory processes such as obtaining institutional agreements and human subject authorizations.

\section{Discussion}

The study findings uphold the viability of implementing a CHW/OT-led lifestyle intervention for rural-dwelling, late midlife Latinos. In support of the intervention's scientific feasibility related to efficacy, a number of positive changes - typically reflecting large effect sizes - in psychosocial patient-centered outcomes were found including symptom severity, perceived impact of symptoms on daily activity, general well-being, satisfaction with social roles, satisfaction with social activities, and stress. Although there is some evidence demonstrating similar positive effects of lifestyle interventions led either by OTs or CHWs (Clark et al., 1997; 2012; Viswanathan et al., 2010), these results support adoption of a hybrid CHW-OT intervention approach.

Intervention recipients' systolic blood pressure declined significantly, an outcome not routinely produced from Latino-tailored lifestyle interventions (Rosal et al., 2011; O'Brien et al., 2015). Because systolic hypertension increases with age, maintaining its level within healthy ranges becomes increasingly important for cardiovascular disease prevention in persons 50 years and older (Chobanian et al., 2003). Notably, the magnitude of systolic blood pressure reduction recorded in the present study was also clinically meaningful, as similar improvements have been associated with reduced risk of cardiac disease or mortality in medication-based trials (Chobanian et al., 2003). Though in a future trial plans will be made to test the precise mechanisms by which the intervention may have reduced blood pressure, it is postulated that participants' reduced intake of sodium, saturated fat, and sugar played an important role (Hall, 2009; Chen et al., 2010; He et al., 2013). Moreover, intervention elements focusing on mental health, stress reduction, self-efficacy, and social support may have enhanced this effect, a possibility consistent with previous reports on the cardiovascular benefits of psychosocial interventions (Linden et al., 1996; Rainforth et al., 2007). Together, evidence points to the need to further explore lifestyle interventions that reach beyond a focus on diet and exercise and extend to psychosocial factors that may positively influence both physiological and mental well-being.

Other physiological parameters did not improve, and coronary heart and diabetes disease risk remained the same. These results are consistent with other $\mathrm{CHW}$-led programs that have shown modest effects at best on cardiometabolic indicators (Rosal et al., 2011; De Heer et al., 2015). One explanation for these findings is that the 16-week intervention did not uniquely target any single disease or delve deeply into physical activity or diet, which is uncharacteristic of traditional lifestyle interventions. However, the intervention was designed to promote holistic wellness as recommended for rural healthcare efforts, in which multiple, targeted services are less practical or feasible (Chipp et al., 2008). In this regard, cardiometabolic parameters associated with certain diseases (eg, HbA1c levels) or specific health behaviors may be difficult to alter through a generalized intervention. Further investigation is warranted to determine the impact that adaptations made to improve the practicality of lifestyle interventions for implementation in a rural primary care context have on the intervention's potential to produce desired health outcomes.

One aspect of ; $V M V$ ! that proved unfeasible was use of the Vivofit activity monitor. The CHWs described the tracker as 'too high-tech' for the target population, resulting in only one participant utilizing it. In other $\mathrm{CHW}$-led programs, incorporating strategies such as providing low-tech pedometers with a goal of 10000 daily steps (Koniak-Griffin et al., 2015) or linking participants 
to community-based physical activity resources such as walking groups (De Heer et al., 2015) resulted in significantly increased physical activity. In planning the next iteration of ; $V M V$ !, our team will more appropriately tailor physical activity strategies to the target population.

Another possible reason for the lack of effect for cardiometabolic indicators is that the four-month program length was too short to affect changes in these parameters. For instance, in one prior study, significant changes in HbA1c levels were not observed until completion of a six-month, promotor-delivered, diabetes-focused program (Lujan et al., 2007). In a further study, Ockene et al. (2012) reported improvements in weight and HbA1c following a lifestyle intervention for Latinos, although their program lasted a full year. Our preliminary findings justify consideration of an extended intervention and assessment period in a future clinical trial.

The process feasibility of ; VMV! is promising. The desired number of intervention participants were efficiently recruited in a one-month time period with assistance from the primary care partners. Moreover, the study demonstrated $77 \%$ participant adherence to the program and 93\% retention of individuals to the time of post-testing. These numbers are successful, given anecdotal reports of $50 \%$ no-show rates for general community programs at AVPH. ;VMV! was delivered with high fidelity, though in future efforts the training workshop and CHW supervision meetings will be bolstered to address areas of concern. For instance, the CHW's underutilization of motivational interviewing may be remedied by expanding the training component that is dedicated to introducing and utilizing the techniques. Nonetheless, the systematic assessment of intervention delivery fidelity featured in this pilot study reveals that the CHWs have full capacity to deliver the core components of a complex OT-CHW intervention with high fidelity.

Participants were extremely satisfied with ¡VMV!. Key stakeholders also found the program to be acceptable and worthy of adopting, but pointed out aspects that could be improved. For example, the OT and the AVPH administrator requested that in future efforts attempts be made to more fully integrate ; $V M V$ ! into the ongoing services offered through patients' primary care institutions (eg, establishing clear expectations for collaboration and reciprocal communication between the primary care and CHW-OT teams regarding treatment and outcomes). Interveners and participants alike experienced difficulties with Wi-Fi during the intervention. Because the Wi-Fi landscape continuously changes, verifying coverage before study initiation will be useful in future applications, and 'offline' solutions, such as using carbon copy paper to capture treatment notes instead of requiring $\mathrm{CHWs}$ to upload digital copies, need to be implemented when indicated.

Among all levels of the process evaluation, the team's ability to improvise emerged as a common theme that facilitated implementation. Whether addressing adherence by allowing participants to make up missed treatment sessions or streamlining treatment documentation so that $\mathrm{CHWs}$ could complete their notes with less difficulty, the ability to undertake in-stream adaptations proved critical. In cases where the team was less adaptable, process feasibility suffered. As an example, because having prearranged groups for each $\mathrm{CHW}$ before initiating the intervention was adhered to, the time between pretesting and the first treatment session was unusually long ( $M=22$ days). Indeed, the success of community-based participatory research hinges on the flexibility with which teams approach and execute process elements (Cook, 2008).

The assessment of the resource feasibility and management feasibility of ; $V M V$ ! revealed the need for slight reconfiguration of time and personnel. Travel time frequently presents an obstacle for rurally situated home health service providers and patients (Buzza et al., 2011), as was the case in this study. During planning stages, the amount of time required for CHWs to travel among participants' homes was underestimated, resulting in a failure to anticipate how this would impact scheduling and caseloads. Future efforts will require strategizing with community partners to identify practical solutions to resource and management shortcomings, discussing strategies such as reducing intervener caseloads, increasing the number of telehealth sessions, and hiring an onsite project coordinator.

\section{Strengths \& limitations}

This study had multiple strengths. The intervention features a pioneering collaboration between OTs and CHWs within primary care. Though each field of practice is independently emerging as a contributor to this healthcare 
context (Brownstein et al., 2011; Donnelly et al., 2013), their co-involvement as a partnered team brings an important, reciprocal skillset to the intervention equation that has not yet been studied. In addition, ; $V M V$ ! is qualitatively distinct from other lifestyle interventions for rural-living Latinos (Brown et al., 2002; Walker et al., 2009; Fahs et al., 2013; Hu et al., 2014; Lilly et al., 2014). It is based on a holistic approach to healthy lifestyle, thereby moving beyond the traditional focus on dietary intake and exercise to encompass pressing daily concerns such as social relationships, mental health, sleep, and stress management. Finally, including patients and all ranks of stakeholders in the development and implementation process of ; $V M V$ ! (Schepens Niemiec et al., 2015) provides a more realistic view of program roll-out in a real-life context.

Despite its strengths, the study also had several limitations. The pretest-posttest design did not include a control group, which leaves study results, particularly for the MYMOP2, susceptible to regression to the mean or other threats to causal inference. Long-term follow-up assessment was not included; however, the team is currently preparing a 12-month follow-up study of the same intervention participants. A small sample was drawn from one primary care facility. A future study will feature a multi-site trial with more participants to improve generalizability. Group session attendance was low in comparison to individualized sessions. A wider variety of locations and time slots for group sessions will be available to participants in a future trial to improve adherence. Use of deductive methods for content analysis of feasibility data - using predetermined thematic categories - limited the richness of data extracted from the interviews. More in-depth interviews with detailed qualitative analysis is warranted. Finally, change in self-reported health outcomes may have been over- or underestimated, owing to recall and social desirability biases.

\section{Conclusion}

The i $V M V$ ! lifestyle intervention is feasible to implement and shows potential to improve a variety of health and wellness outcomes in late middleaged Latino patients from a rural community. This study is significant because it serves as a springboard to change clinical practice in primary care. Unlike other interventions, ;VMV! combined the specialties of CHWs and OTs to encourage a hard-to-reach patient population to incorporate general healthy lifestyle changes into their daily routines. Although a number of challenges arose which can potentially be minimized through programmatic tweaks, this study demonstrated one way in which CHWs and OTs can effectively collaborate to address the health needs of underserved populations within rural primary care. Given the promise that ; $V M V$ ! shows, and the health risks that present in rural-living Latinos, a future randomized controlled trial is warranted to further investigate the efficacy of this lifestyle intervention.

\section{Acknowledgments}

The authors would like to thank the participants and also Antelope Valley Partners for Health, Antelope Valley Community Clinic, and Southern California Clinical and Translational Science Institute for their support of this project.

\section{Financial Support}

This work was supported by the National Institutes of Health - National Center for Medical and Rehabilitation Research and National Institute for Neurological Disorders \& Stroke (Schepens Niemiec, grant \# K12 HD055929); and an internal award through the University of Southern California OS/OT Initiatives Program (Schepens Niemiec).

\section{Conflicts of Interest}

None.

\section{Ethical Standards}

The authors assert that all procedures contributing to this work comply with the ethical standards of the University of Southern California Institutional Review Board and with the Helsinki Declaration of 1975 , as revised in 2008.

\section{References}

Backhaus, J., Junghanns, K., Broocks, A., Riemann, D. and Hohagen, F. 2002: Test-retest reliability and validity of the Pittsburgh Sleep Quality Index in primary insomnia. Journal of Psychosomatic Research 53, 737-40.

Bale, B. 2010: Optimizing hypertension management in underserved rural populations. Journal of the National Medical Association 102, 10-17. 
Bandura, A. 1986. Social foundations of thought and action. Englewood Cliffs, NJ: Prentice-Hall.

Bandura, A. 2004: Health promotion by social cognitive means. Health Education \& Behavior 31, 143-64.

Berg, B.L. 2001. Qualitative research methods for the social sciences. Boston, MA: Allyn and Bacon.

Brown, S.A., Garcia, A.A., Kouzekanani, K. and Hanis, C.L. 2002: Culturally competent diabetes self-management education for Mexican Americans: The Starr County Border Health Initiative. Diabetes Care 25, 259-68.

Brownstein, J.N., Hirsch, G.R., Rosenthal, E.L. and Rush, C.H. 2011: Community health workers " 101 " for primary care providers and other stakeholders in health care systems. The Journal of Ambulatory Care Management 34, 210-20.

Buzza, C., Ono, S.S., Turvey, C., Wittrock, S., Noble, M., Reddy, G., Kaboli, P.J. and Reisinger, H.S. 2011: Distance is relative: unpacking a principal barrier in rural healthcare. Journal of General Internal Medicine 26, 648-54.

Calancie, L., Leeman, J., Jilcott Pitts, S.B., Khan, L.K., Fleischhacker, S., Evenson, K.R., Schreiner, M., Byker, C., Owens, C., Mcguirt, J., Barnidge, E., Dean, W., Johnson, D., Kolodinsky, J., Piltch, E., Pinard, C., Quinn, E., Whetstone, L. and Ammerman, A. 2015: Nutrition-related policy and environmental strategies to prevent obesity in rural communities: a systematic review of the literature, 2002-2013. Preventing Chronic Disease 12, E57.

Carlson, M., Clark, F. and Young, B. 1998: Practical contributions of occupational science to the art of successful ageing: how to sculpt a meaningful life in older adulthood. Journal of Occupational Science 5, 107-18.

Cella, D., Riley, W., Stone, A., Rothrock, N., Reeve, B., Yount, S., Amtmann, D., Bode, R., Buysse, D. and Choi, S. 2010: The Patient-Reported Outcomes Measurement Information System (PROMIS) developed and tested its first wave of adult self-reported health outcome item banks: 2005-2008. Journal of Clinical Epidemiology 63, 1179-194.

Centers for Disease Control and Prevention 2015: National Health and Nutrition Examination Survey. Retrieved 9 August 2016 from http://www.cdc.gov/nchs/nhanes/nhanes_ questionnaires.htm.

Charlson, M.E., Pompei, P., Ales, K.L. and Mackenzie, C.R. 1987: A new method of classifying prognostic comorbidity in longitudinal studies: development and validation. Journal of Chronic Diseases 40, 373-83.

Chen, L., Caballero, B., Mitchell, D.C., Loria, C., Lin, P.H., Champagne, C.M., Elmer, P.J., Ard, J.D., Batch, B.C., Anderson, C.A. and Appel, L.J. 2010: Reducing consumption of sugar-sweetened beverages is associated with reduced blood pressure: a prospective study among United States adults. Circulation 121, 2398-406.

Chipp, C.L., Johnson, M.E., Brems, C., Warner, T.D. and Roberts, L.W. 2008: Adaptations to health care barriers as reported by rural and urban providers. Journal of Health Care for the Poor and Underserved 19, 532-49.

Chobanian, A.V., Bakris, G.L., Black, H.R., Cushman, W.C., Green, L.A., Izzo, J.L. Jr., Jones, D.W., Materson, B.J.,
Oparil, S., Wright, J.T. Jr., Roccella, E.J., Joint National Committee on Prevention, Detection, Evaluation, and Treatment of High Blood Pressure. National Heart, Lung, and Blood Institute; National High Blood Pressure Education Program Coordinating Committee 2003: Seventh report of the Joint National Committee on Prevention, Detection, Evaluation, and Treatment of High Blood Pressure. Hypertension 42, 1206-252.

Clark, F., Azen, S.P., Zemke, R., Jackson, J., Carlson, M., Mandel, D., Hay, J., Josephson, K., Cherry, B., Hessel, C., Palmer, J. and Lipson, L. 1997: Occupational therapy for independent-living older adults: a randomized controlled trial. Journal of the American Medical Association 278, 1321-326.

Clark, F., Blanchard, J., Sleight, A., Cogan, A., Floríndez, L., Gleason, S., Heymann, R., Hill, V., Holden, A., Murphy, M., Proffitt, R., Schepens Niemiec, S.L. and Vigen, C. 2015. Lifestyle redesign: the intervention tested in the USC well elderly studies. Bethesda, MD: AOTA Press.

Clark, F., Jackson, J., Carlson, M., Chou, C.P., Cherry, B.J., Jordan-Marsh, M., Knight, B.G., Mandel, D., Blanchard, J., Granger, D.A., Wilcox, R.R., Lai, M.Y., White, B., Hay, J., Lam, C., Marterella, A. and Azen, S.P. 2012: Effectiveness of a lifestyle intervention in promoting the well-being of independently living older people: results of the well elderly 2 randomised controlled trial. Journal of Epidemiology and Community Health 66, 782-90.

Cole, J.C., Motivala, S.J., Buysse, D.J., Oxman, M.N., Levin, M.J. and Irwin, M.R. 2006: Validation of a 3-factor scoring model for the Pittsburgh sleep quality index in older adults. Sleep 29, 112-16.

Cook, W. K. 2008: Integrating research and action: a systematic review of community-based participatory research to address health disparities in environmental and occupational health in the USA. Journal of Epidemiology and Community Health 62, 668-76.

Craig, C., Marshall, A., Sjöström, M., Bauman, A., Booth, M., Ainsworth, B., Pratt, M., Ekelund, U., Yngve, A. and Sallis, J. 2003: International physical activity questionnaire: 12 -country reliability and validity. Medicine \& Science in Sports \& Exercise 35, 1381-395.

Daviglus, M.L., Talavera, G.A., Aviles-Santa, M.L., Allison, M., Cai, J., Criqui, M.H., Gellman, M., Giachello, A.L., Gouskova, N., Kaplan, R.C., Lavange, L., Penedo, F., Perreira, K., Pirzada, A., Schneiderman, N., WassertheilSmoller, S., Sorlie, P.D. and Stamler, J. 2012: Prevalence of major cardiovascular risk factors and cardiovascular diseases among Hispanic/Latino individuals of diverse backgrounds in the United States. Journal of the American Medical Association 308, 1775-784.

de Heer, H.D., Balcazar, H.G., Wise, S., Redelfs, A.H., Rosenthal, E.L. and Duarte, M.O. 2015: Improved cardiovascular risk among Hispanic border participants of the Mi Corazon Mi Comunidad Promotores De Salud Model: The HEART II Cohort Intervention Study 2009-2013. Frontiers in Public Health 3, 1-7. 
De Smedt, D., Clays, E., Annemans, L., Doyle, F., Kotseva, K., Pajak, A., Prugger, C., Jennings, C., Wood, D. and De Bacquer, D. 2013: Health related quality of life in coronary patients and its association with their cardiovascular risk profile: results from the EUROASPIRE III survey. International Journal of Cardiology 168, 898-903.

Donnelly, C., Brenchley, C., Crawford, C. and Letts, L. 2013: The integration of occupational therapy into primary care: a multiple case study design. BMC Family Practice 14, 60.

Elo, A.-L., Leppänen, A. and Jahkola, A. 2003: Validity of a single-item measure of stress symptoms. Scandinavian Journal of Work, Environment \& Health 29, 444-51.

Fahs, P.S., Pribulick, M., Williams, I.C., James, G.D., Rovnyak, V. and Seibold-Simpson, S.M. 2013: Promoting heart health in rural women. Journal of Rural Health 29, 248-57.

Goldhaber-Fiebert, J.D., Goldhaber-Fiebert, S.N., Tristan, M.L. and Nathan, D.M. 2003: Randomized controlled community-based nutrition and exercise intervention improves glycemia and cardiovascular risk factors in type 2 diabetic patients in rural Costa Rica. Diabetes Care 26, 24-29.

Hall, W.L. 2009: Dietary saturated and unsaturated fats as determinants of blood pressure and vascular function. Nutrition Research Reviews 22, 18-38.

Hansen-Kyle, L. 2005: A concept analysis of healthy aging. Nursing Forum 40, 45-57.

Harris, P.A., Taylor, R., Thielke, R., Payne, J., Gonzalez, N. and Conde, J.G. 2009: Research electronic data capture (REDCap) - a metadata-driven methodology and workflow process for providing translational research informatics support. Journal of Biomedical Informatics 42, 377-81.

Hayward, M. D., Hummer, R. A., Chiu, C. T., GonzalezGonzalez, C. and Wong, R. 2014: Does the Hispanic paradox in U.S. adult mortality extend to disability? Population Research and Policy Review 33, 81-96.

He, F.J., Li, J. and Macgregor, G.A. 2013: Effect of longer term modest salt reduction on blood pressure: Cochrane systematic review and meta-analysis of randomised trials. British Medical Journal 346, 1-15.

Hibbard, J.H., Mahoney, E.R., Stockard, J. and Tusler, M. 2005: Development and testing of a short form of the patient activation measure. Health Services Research 40, 1918-930.

Housing Assistance Council. 2012. Race \& ethnicity in rural America. Rural research brief. Washington, DC: Housing Assistance Council.

Hu, J., Wallace, D.C., Mccoy, T.P. and Amirehsani, K.A. 2014: A family-based diabetes intervention for Hispanic adults and their family members. The Diabetes Educator 40, 48-59.

Koniak-Griffin, D., Brecht, M.L., Takayanagi, S., Villegas, J., Melendrez, M. and Balcazar, H. 2015: A community health worker-led lifestyle behavior intervention for Latina (Hispanic) women: feasibility and outcomes of a randomized controlled trial. International Journal of Nursing Studies 52, 75-87.
Koopman, R.J., Mainous, A.G. III and Geesey, M.E. 2006: Rural residence and Hispanic ethnicity: doubly disadvantaged for diabetes? The Journal of Rural Health 22, 63-68.

Latino Health Access, Visión Y Compromiso \& Esperanza Community Housing Corporation 2011: The promotor model - a model for building healthy communities. Retrieved 3 March 2017 from http://www.visionycompromiso.org/word press/wp-content/uploads/TCE_Promotores-Framing-Paper. pdf.

Lilly, C.L., Bryant, L.L., Leary, J.M., Vu, M.B., Hill-Briggs, F., Samuel-Hodge, C.D., Mcmilin, C.R. and Keyserling, T.C. 2014: Evaluation of the effectiveness of a problem-solving intervention addressing barriers to cardiovascular disease prevention behaviors in 3 underserved populations: Colorado, North Carolina, West Virginia, 2009. Preventing Chronic Disease 11, E32.

Linden, W., Stossel, C. and Maurice, J. 1996: Psychosocial interventions for patients with coronary artery disease: a meta-analysis. Archives of Internal Medicine 156, 745-52.

Lujan, J., Ostwald, S.K. and Ortiz, M. 2007: Promotora diabetes intervention for Mexican Americans. The Diabetes Educator 33, 660-70.

Lutfiyya, M.N., Bianco, J.A., Quinlan, S.K., Hall, C. and Waring, S.C. 2012: Mental health and mental health care in rural America: the hope of redesigned primary care. Disease-a-Month 58, 629-38.

Lutfiyya, M.N., Mccullough, J.E., Saman, D.M., Lemieux, A., Hendrickson, S., Mcgrath, C.A., Haller, I.V. and Lipsky, M.S. 2013: Rural/urban differences in health services deficits among US adults with arthritis: a population-based study. Journal of Nursing Education and Practice 3, 43-53.

Michie, S., Ashford, S., Sniehotta, F.F., Dombrowski, S.U., Bishop, A. and French, D.P. 2011: A refined taxonomy of behaviour change techniques to help people change their physical activity and healthy eating behaviours: The CALORE taxonomy. Psychology \& Health 26, 1479-498.

Nuttall, F. Q. 2015: Body mass index: obesity, BMI, and health: a critical review. Nutrition Today 50, 117-28.

O'Brien, M.J., Perez, A., Alos, V.A., Whitaker, R.C., Ciolino, J.D., Mohr, D.C. and Ackermann, R.T. 2015: The feasibility, acceptability, and preliminary effectiveness of a Promotora-Led Diabetes Prevention Program (PL-DPP) in Latinas: a pilot study. The Diabetes Educator 41, 485-94.

Ockene, I.S., Tellez, T.L., Rosal, M.C., Reed, G.W., Mordes, J., Merriam, P.A., Olendzki, B.C., Handelman, G., Nicolosi, R. and Ma, Y. 2012: Outcomes of a Latino community-based intervention for the prevention of diabetes: The Lawrence Latino Diabetes Prevention Project. American Journal of Public Health 102, 336-42.

Osuna, D., Barrera, M. Jr., Strycker, L.A., Toobert, D.J., Glasgow, R.E., Geno, C.R., Almeida, F., Perdomo, M., King, D. and Doty, A.T. 2011: Methods for the cultural adaptation of a diabetes lifestyle intervention for Latinas: an illustrative project. Health Promotion Practice 12, 341-48.

Parikh, P., Simon, E.P., Fei, K., Looker, H., Goytia, C. and Horowitz, C.R. 2010: Results of a pilot diabetes prevention 
intervention in East Harlem, New York City: Project HEED. American Journal of Public Health 100, S232-239.

Paterson, C. 1996: Measuring outcomes in primary care: a patient generated measure, MYMOP, compared with the SF-36 health survey. British Medical Journal 312, 1016-20.

Paterson, C., Langan, C., Mckaig, G., Anderson, P., Maclaine, G., Rose, L., Walker, S. and Campbell, M. 2000: Assessing patient outcomes in acute exacerbations of chronic bronchitis: The measure your medical outcome profile (MYMOP), medical outcomes study 6-item general health survey (MOS-6A) and EuroQol (EQ-5D). Quality of Life Research 9, 521-27.

Patton, M.Q. 2001. Qualitative research and evaluation methods. Thousand Oaks, CA: Sage Publications.

Perepletchikova, F. and Kazdin, A.E. 2005: Treatment integrity and therapeutic change: issues and research recommendations. Clinical Psychology: Science and Practice 12, 365-83.

Polus, B.I., Kimpton, A.J. and Walsh, M.J. 2011: Use of the measure your medical outcome profile (MYMOP2) and W-BQ12 (Well-Being) outcomes measures to evaluate chiropractic treatment: an observational study. Chiropractic \& Manual Therapies 19, 7.

Rainforth, M.V., Schneider, R.H., Nidich, S.I., Gaylord-King, C., Salerno, J.W. and Anderson, J.W. 2007: Stress reduction programs in patients with elevated blood pressure: a systematic review and meta-analysis. Current Hypertension Reports 9, 520-28.

Rosal, M.C., Ockene, I.S., Restrepo, A., White, M.J., Borg, A., Olendzki, B., Scavron, J., Candib, L., Welch, G. and Reed, G. 2011: Randomized trial of a literacy-sensitive, culturally tailored diabetes self-management intervention for low-income latinos: Latinos en Control. Diabetes Care 34, 838-44.

Rubenfeld, G.D. 2003. Surrogate measures of patient-centered outcomes in critical care. Surviving Intensive Care. Berlin: Springer Berlin Heidelberg.

Sanchez, V., Cacari Stone, L., Moffett, M.L., Nguyen, P., Muhammad, M., Bruna-Lewis, S. and Urias-Chauvin, R. 2014: Process evaluation of a promotora de salud intervention for improving hypertension outcomes for Latinos living in a rural U.S.-Mexico border region. Health Promotion Practice 15, 356-64.

Schepens Niemiec, S.L., Blanchard, J., Vigen, C., Vigen Martínez, J., Guzmán, L., Fluke, M. and Carlson, M. In Press: A pilot study of the ;Vivir Mi Vida! lifestyle intervention for rural-dwelling, late-midlife Latinos: Study design and protocol. OTJR: Occupation, Participation and Health.

Schepens Niemiec, S.L., Carlson, M., Martínez, J., Guzmán, L., Mahajan, A. and Clark, F. 2015: Developing occupationbased preventive programs for late-middle-aged Latino patients in safety-net health systems. American Journal of Occupational Therapy 69, 1-11.

Schulze, M.B., Hoffmann, K., Boeing, H., Linseisen, J., Rohrmann, S., Möhlig, M., Pfeiffer, A. F., Spranger, J., Thamer, C. and Häring, H.-U. 2007: An accurate risk score based on anthropometric, dietary, and lifestyle factors to predict the development of type 2 diabetes. Diabetes Care 30, 510-15.

Scullin, M.K. and Bliwise, D.L. 2015: Sleep, cognition, and normal aging: integrating a half century of multidisciplinary research. Perspectives on Psychological Science 10, 97-137.

Sociocultural Research Consultants, LLC 2017. Dedoose Version 7.5.9, web application for managing, analyzing, and presenting qualitative and mixed method research data. Los Angeles, CA: SocioCultural Research Consultants, LLC.

Sudano, J. J. and Baker, D. W. 2006: Explaining US racial/ ethnic disparities in health declines and mortality in late middle age: the roles of socioeconomic status, health behaviors, and health insurance. Social Science \& Medicine 62, 909-22.

Swenson, C.J., Marshall, J.A., Mikulich-Gilbertson, S.K., Baxter, J. and Morgenstern, N. 2005: Physical activity in older, rural, Hispanic, and non-Hispanic white adults. Medicine \& Science in Sports \& Exercise 37, 995-1002.

Thabane, L., Ma, J., Chu, R., Cheng, J., Ismaila, A., Rios, L.P., Robson, R., Thabane, M., Giangregorio, L. and Goldsmith, C.H. 2010: A tutorial on pilot studies: the what, why and how. BMC Medical Research Methodology 10, 1.

Verhoef, M.J., Mulkins, A. and Boon, H. 2005: Integrative health care: How can we determine whether patients benefit? The Journal of Alternative and Complementary Medicine 11 (Suppl 1), S57-65.

Vincent, G. K. and Velkoff, V. A. 2010. The next four decades. The older population in the United States: 2010-2050. Washington, DC: US Census Bureau.

Viswanathan, M., Kraschnewski, J.L., Nishikawa, B., Morgan, L.C., Honeycutt, A.A., Thieda, P., Lohr, K.N. and Jonas, D.E. 2010: Outcomes and costs of community health worker interventions: a systematic review. Medical Care 48, 792-808.

Walker, S.N., Pullen, C.H., Boeckner, L., Hageman, P.A., Hertzog, M., Oberdorfer, M.K. and Rutledge, M.J. 2009: Clinical trial of tailored activity and eating newsletters with older rural women. Nursing Research 58, 74-85.

Weinhold, I. and Gurtner, S. 2014: Understanding shortages of sufficient health care in rural areas. Health Policy 118, 201-14.

Wilson, P.W., D'agostino, R.B., Levy, D., Belanger, A.M., Silbershatz, H. and Kannel, W.B. 1998: Prediction of coronary heart disease using risk factor categories. Circulation 97, 1837-847. 